\title{
BMJ Open Level and predictors of dietary diversity among pregnant women in rural South- West Ethiopia: a community-based cross-sectional study
}

\author{
Melesse Niguse Kuma (D), Dessalegn Tamiru, Tefera Belachew
}

To cite: Kuma MN, Tamiru D, Belachew T. Level and predictors of dietary diversity among pregnant women in rural South-West Ethiopia: a community-based crosssectional study. BMJ Open 2021;11:e055125. doi:10.1136/ bmjopen-2021-055125

- Prepublication history for this paper is available online. To view these files, please visit the journal online (http://dx.doi. org/10.1136/bmjopen-2021055125).

Received 10 July 2021 Accepted 28 September 2021

Check for updates

(c) Author(s) (or their employer(s)) 2021. Re-use permitted under CC BY-NC. No commercial re-use. See rights and permissions. Published by BMJ.

Department of Nutrition and Dietetics, Jimma University College of Public Health and Medical Sciences, Jimma, Oromia, Ethiopia

Correspondence to Melesse Niguse Kuma; meleseniguse@gmail.com

\section{ABSTRACT}

Objective To assess the magnitude of dietary diversity and associated factors among pregnant women in the rural communities of Jimma Zone, south-west Ethiopia. Design A community-based cross-sectional study was conducted from 1 June to 30 June 2020.

Settings The study was conducted in Seka Chekorsa and Mana districts. From a total of 63 listed kebeles, 21 were randomly selected.

Participants Three hundred sixty first-trimester pregnant women have participated in this study. We used a systematic random sampling method to select the participants after a home-to-home census.

Primary and secondary outcomes Dietary diversity was assessed using a 24 hours dietary recall method. Descriptive statistics were computed to describe the study subjects. Bivariate and multivariable logistic regression was run to control for all possible confounding effects and measure the strength of association between the outcome of interest and predictor.

Results The overall magnitude of adequate dietary diversity was found to be $186(51.7 \%) ; 95 \% \mathrm{Cl} 46.1 \%$ to $56.4 \%)$. Having attended elementary education (adjusted $\mathrm{OR}(\mathrm{AOR})=2.45 ; 95 \% \mathrm{Cl} 1.33$ to 4.51 ), completed grade $8(\mathrm{AOR}=6.05 ; 95 \% \mathrm{Cl} 2.65$ to 13.80$)$, attended high school (AOR=11.69; 95\% $\mathrm{Cl} 3.76$ to 36.27$)$, completed high school and above (AOR=2.92; 95\% $\mathrm{Cl} 1.16$ to 7.32), husbands attended high school (AOR=2.92; 95\% $\mathrm{Cl} 1.15$ to 7.47 ), family size of less than five ( $A O R=3.44 ; 95 \% \mathrm{Cl}$ to 1.77-6.66) were positively significantly associated with adequate dietary diversity. On the other hand, not had additional meal during pregnancy $(\mathrm{AOR}=0.42 ; 95 \% \mathrm{Cl} 0.21$ to 0.83 ) was negatively associated with adequate dietary diversity.

Conclusions We observed that the adequate dietary diversity score of pregnant women was low compared with the pooled proportion of dietary diversity conducted in Ethiopia. Therefore, strengthening and promoting female education through intersectoral collaborations and additional meal counselling during pregnancy is indispensable.

\section{INTRODUCTION}

A healthy diet consists of a variety of safe foods that meet the varying nutritional requirements of different population
Strengths and limitations of this study

- It is a community-based cross-sectional study that makes it a representation of the target population.

- It considers that the known agroecology of the area helps to generalise the findings to the study area.

- The dietary diversity score was based on self-report and it might be subjected to some level of recall bias.

- Due to the cross-sectional nature of the study, it does not show the temporal or causal effect relationships between the independent and the outcome variables.

- Also, the study design does not allow to consider the seasonal variations.

subgroups. ${ }^{1}$ This is aligned with the fact that pregnancy is physiologically the most nutritionally demanding period of life. ${ }^{2}$ During this critical time, nutritional deficits may lead to irreversible, but preventable physical and cognitive impairments. ${ }^{3}$ Dietary diversity is the consumption of various foods from different food groups that allows getting adequate essential nutrients that can shore up the well-being of the body and mental development. ${ }^{4}$ Thus, dietary diversity is among the highly advisable nutritional methods to prevent malnutrition by providing nutrientdense food groups in their day-to-day meals to achieve the required nutrient adequacy of pregnant women. ${ }^{56}$ Moreover, dietary diversity is a very crucial element to avoid micronutrient deficiencies and to promote good health. ${ }^{7}$ Therefore, the dietary diversity of pregnant women needs to be improved to ensure getting the adequate quality of diet and reduce the consequence of poor dietary diversity. ${ }^{8}$ Studies have reported that dietary diversity of pregnant women is associated with many factors. Among these, maternal educational status, ${ }^{710-13}$ meal frequency, ${ }^{10} 1214$ wealth index, ${ }^{1516}$ and maternal occupations like being governmentally employed and 
merchants were some of them. ${ }^{14}{ }^{16}$ Recently, many of the global nutrition efforts have focused on women during pregnancy and children in the first 1000 days, which is considered as a window of opportunity to improve maternal and child outcomes. ${ }^{17}$ Especially, in developing countries, maternal diet is monotonous and predominantly plant-based with little consumption of nutrientdense animal source foods, fruits and vegetables as they are not accessible due to poverty. ${ }^{18}$ Likewise, the diet of pregnant women in Ethiopia is characterised as monotonous and predominantly cereal-based, with very low or no consumption of fruits and vegetables with no change in their diet. ${ }^{19} 20$

Cognizant of this, even though the government has made tremendous efforts, the burden of undernutrition among pregnant women of Ethiopia is still unacceptably high. ${ }^{21-23}$ In the country, even though there were reports about the dietary diversity of pregnant women, most of the reports were from towns or cities and institutional bases. Because of this, identifying community-based specific factors related to the dietary diversity of rural pregnant women is very critical to design evidence-based appropriate long-term nutritional intervention strategies that would optimise pregnancy and fetal outcomes. Although Jimma Zone is evergreen and there is a production of different kinds of fruits and vegetables in the area, there is no study that evaluated the dietary diversity of pregnant women, especially in rural communities. Therefore, this study aimed to assess the magnitude of dietary diversity and associated factors among pregnant women in the rural communities of Jimma Zone, South-West Ethiopia.

\section{METHODS AND MATERIALS}

\section{Study design, setting and participants}

A community-based cross-sectional study design was conducted in Mana and Seka Chekorsa districts of Jimma Zone, South-West Ethiopia from 1 June to 30 June 2020. The zone is found $345 \mathrm{~km}$ away from the capital city of the country, Addis Ababa in the south-west direction. Jimma Zone is one of the leading coffee-producing zones of Oromia Regional State with annual rainfall ranging between $1200 \mathrm{~mm}$ and $2800 \mathrm{~mm}$ per annum. Jimma Zone has two known agroecological (coffee-growing and food crop-growing) districts. Accordingly, Mana was selected mainly from coffee-growing districts. Khat was also another important cash crop in this area. Mana was found at $1911 \mathrm{~m}$ altitude above sea level with an estimated total population of 160 096, of whom 80481 were men and 79615 were women. The district had 26 kebeles (the smallest administrative units) including Yebu and Bilida Towns. The other selected district was Seka Chekorsa mainly consisting of grain-producing and food cropproducing districts (like fruits, teff, peppers and Khat). It had an altitude between $1580 \mathrm{~m}$ and $2560 \mathrm{~m}$ above sea level and an estimated total population of 336 277, of whom 168863 were men and 167414 were women. This district had 37 kebeles (the smallest administrative

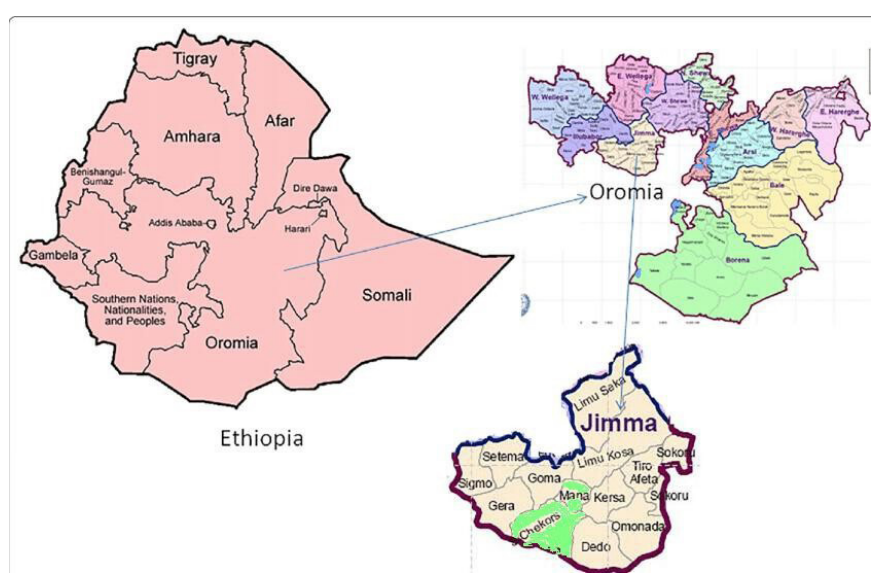

Figure 1 Map of the study area of the predictors of diet diversity among pregnant women in rural communities of South-West Ethiopia, 2020.

units) including the two town kebeles of Seka. Kebele is the smallest governmental administrative unit in the country. Of 12351 expected pregnant women in both districts, about 4117 were in the first trimester. The study was carried out among first-trimester pregnant mothers 15-49 years old from 1 June to 30 June 2020 (figure 1).

The details of the methods including study settings, sampling techniques, inclusion and exclusion criteria are described elsewhere. ${ }^{24}$

\section{Sample size determination and sampling technique}

The sample size was determined by using a single population proportion formula, with the assumption of a $95 \%$ confidence level $\left(\mathrm{Z} \mathrm{\alpha /}{ }_{2}\right)$ and 0.05 expected margin of error (d). Since we have two objectives we have calculated the sample size for both to take the larger sample size.

For the first objective, we took the proportion (p) of poor diet diversity among pregnant women to be $36.1 \%$ from the study done in Jimma town. ${ }^{25}$

$$
\mathrm{n}=\left(Z \frac{\alpha}{2}\right)^{2} \frac{P(1-p)}{d^{2}}
$$

where $Z \frac{\alpha}{2}=95 \%$ level of confidence (1.96), p=estimated proportion, $\mathrm{d}=$ margin of error $\underline{2}$

$$
\mathrm{n}=\frac{(1.96)^{2} 0.361(1-0.361)}{(0.05)^{2}}=\frac{3.84 \times(0.361 \times 0.639)}{0.0025} \approx 355
$$

For the second objective, we calculated by using the double population proportion formula for commonly associated factors of diet diversity from previous studies.

$$
\mathrm{n}=\frac{[P 1(1-P 1)+P 2(1-P 2)]}{(P 1-P 2)^{2}}(\mathrm{Z} \alpha / 2+\mathrm{Z} \beta) 2
$$

where, $\mathrm{n}=$ required sample size, $P 1=$ estimated proportion of study outcome in the exposed group, $P 2=$ estimated proportion of study outcome in the unexposed group, $\alpha=$ level of statistical significance, $Z \alpha / 2$ $=$ the desired level of statistical significance $(1.96$ for $\alpha=0.05), Z \beta=$ the desired power $(0.84$ for $80 \%$ power), $\mathrm{n}$ for each group* $2=$ total sample (ie, for the two groups). 
Accordingly, we have calculated for maternal educational status by using the prevalence of inadequate diet diversity $(5.53 \%)$ and adequate dietary diversity $(43.75 \%)$ among pregnant women who attended college and above from the study conducted in Shashemane, Central Oromia attending antenatal clinic.

$$
\frac{[0.0553(1-0.0553)+0.4375(1-0.4375)]}{(0.0553-0.4375)^{2}}(1.96+0.84)^{2}
$$

$$
\begin{aligned}
& \mathrm{n}=5.26(1.96+0.84)^{2}=5.26(7.84) \\
& \mathrm{n}=42 * 2=84 .
\end{aligned}
$$

Since it is an unequal proportion, we adjusted the sample size $\left({ }_{n \text { adjusted }}\right)$ by using the following formula: ${ }^{26}$

$$
\mathrm{n} \text { adjusted }=\frac{\mathrm{n} \times(\mathrm{k}+1)}{4 \mathrm{k}}
$$

where,

n: sample size=total sample (ie, for the two groups)

$\mathrm{N}=211$.

Similarly, we have calculated for household income status by using the prevalence of inadequate diet diversity $(2.53 \%)$ and adequate dietary diversity $(27.50 \%)$ among pregnant women whose household monthly income was above 3500 Ethiopian birrs from the study conducted in Shashemane, Central Oromia attending antenatal clinic.

$$
\frac{[0.0253(1-0.0253)+0.275(1-0.275)]}{(0.0253-0.275)^{2}}(1.96+0.84)^{2}
$$

$$
\mathrm{n}=3.6(1.96+0.84)^{2}=5.26(7.84)
$$

$\mathrm{n}=29 * 2=58$.

By using the above formula we adjusted the sample size according to the actual ratio of the two groups. Thus,

$$
\frac{58(10.86+1)^{2}}{4(10.86)}
$$

$\mathrm{N}=188$.

Therefore, we decided to use the sample size calculated by using the first objective.

After adding $10 \%$ for non-response rate, the required total sample size was 391. A list of all kebeles in both districts (37 from Seka Chekorsa and 26 from Mana) was made and a unique identification number was assigned to each. From a total of 63 listed kebeles, 21 were selected by a simple random sampling technique. Then, the sample size was allocated proportionally to each kebele and first-trimester pregnant women were selected using a systematic random sampling method. The sampling frame of the study participants of each kebele was made after home-to-home census. If a woman was absent from her house during the interview, eligible pregnant women in the next house in the serial number were interviewed. First-trimester pregnant women who were absent from home were revisited the next day. The pregnancy was confirmed by ultrasound scanning and pregnancies that were diagnosed as non-viable or had incurable deformities were referred to the nearby health institutions for management.

\section{Study variables}

\section{Outcome variables}

The outcome variables of this study were adequate dietary diversity and adequate dietary diversity scores.

\section{Independent variables}

The independent variables included in the analyses of this study were sociodemographic and economic factors such as age, ethnicity, religion, educational status, occupation, marital status, family size, household head, source of drinking water, mass media usage and wealth index. The second category was obstetrics and pregnancy-related variables which included gestational age, parity, interpregnancy interval, history of abortion, history of stillbirth, history of caesarean section and history of nausea/ vomiting. The third category was variables related to dietary practices; own fruits/vegetables, additional meals, food changes during pregnancy, food taboos, iron folate use, coffee consumption and khat chewing.

\section{Data collection and measurements}

The data were collected using a pretested intervieweradministered structured questionnaire. Data were collected by eight experienced and trained midwives (BSc holders) who were familiar with the study area and could speak the local language 'Afan Oromo'. In this study, the Minimum Diet Diversity Score was defined as the number of different food groups consumed over a given reference period. It was created by summing up the number of food groups consumed over 24 hours (a day before data collection) by the mother to 10 and dichotomising according to the Food and Agricultural Organization (FAO) and Family Health International (FHI) 360, 2016 guidelines. ${ }^{27}$ Thus, consumption of at least five or more food groups indicates adequate dietary diversity. We used a multiple pass 24 hours recall method to decrease the bias (table 1).

\section{Operational definitions}

Adequate dietary diversity

When a woman consumed food from five or more food groups on the day/within 24 hours/before data collection. ${ }^{27}$

\section{Inadequate dietary diversity}

When a woman consumed food from less than five food groups on the day/within 24 hours/before data collection. ${ }^{27}$

\section{Minimum diet diversity score}

It is the number of food groups consumed by a woman over 24 hours (a day before data collection). ${ }^{27}$

\section{Data quality control}

The questionnaire was translated into the local language (Afan Oromo) and 3 days of intensive training was given for data collectors and supervisors on the data collection instruments. A practical test was administered for data collectors to make sure that the skill was appropriately 
Table 1 Food groups used for dietary diversity scores among pregnant women of rural South-West Ethiopia, 2020

\begin{tabular}{ll}
\hline Food groups & Subgroups \\
\hline Starchy foods & $\begin{array}{l}\text { Cereals, grains, white roots and } \\
\text { tubers }\end{array}$ \\
\hline Pulses & $\begin{array}{l}\text { Beans, peas and lentils } \\
\text { Nuts and seeds (such as } \\
\text { peanuts, oilseeds, pumpkin } \\
\text { seeds) }\end{array}$ \\
\hline Milk and milk products & $\begin{array}{l}\text { Dairy products such as milk, } \\
\text { butter, cheese and whey }\end{array}$ \\
\hline Meat & $\begin{array}{l}\text { Organ meat (liver, kidney, heart } \\
\text { and other processed foods), meat } \\
\text { (beef, lamb, goat meat), chicken } \\
\text { and fish }\end{array}$ \\
\hline Eggs & $\begin{array}{l}\text { Chicken eggs and quail eggs } \\
\text { Locally available leafy vegetables } \\
\text { such as kale, lettuce, spinach } \\
\text { vegetables }\end{array}$ \\
\hline Vitamin A-rich fruits and \\
vegetables
\end{tabular}

transferred. In addition to this, two trained supervisors were assigned to give on-site support and oversee the completeness of the collected data overnight. A pretest was conducted on $5 \%$ of the total sample in the Kersa district, the non-selected setting of Jimma Zone.

\section{Data processing and analysis}

Data were checked for completeness, consistency and accuracy. Then, it was entered into Epi-data V.3.1 and exported to STATA V.13 for data cleaning and analysis. Descriptive statistics such as mean, frequency and percentages were used to describe the study subjects. Binary and multivariable logistic regression analyses were used to see the association between the explanatory and the outcome variables. Variables with a value of $\mathrm{p}<0.2$ during bivariate logistic regression analyses were selected as candidates for the multivariable logistic regression model to control for all possible confounding effects. Crude and adjusted ORs (AOR) along with 95\% CIs were used to estimate the strength of association. Variables having a value of $p<0.05$ in the backward stepwise multivariable logistic regression were considered as significantly associated with the dependent variable. The goodness of fit for the final logistic model was tested using the Hosmer and Lemeshow test at $>0.05(p=0.43)$. Multicollinearity was checked by using the correlation coefficient of the matrix. The highest observed correlation among the independent variables was $r=0.19$. The wealth index was estimated as a composite indicator of living standards by considering 29 variables related to ownership of household durable assets (both productive and non-productive assets). Before conducting the principal component analysis, assumptions of the overall sampling adequacy (KaiserMeyer-Olkin measurement of sampling $(\mathrm{KMO})>0.5)$, Bartlett's test of sphericity ( $\mathrm{p} \leq 0.05)$, having commonality $>0.5$, not having the complex structure correlation $\geq 0.40$ were checked. The components that collectively explained more than $60 \%$ of the variance in the set of variables were used for generation of continuous variable. It was done by summing up the principal components into one and making the tertile rank.

\section{Patient and public involvement}

In this study, the patients or the public were not directly involved in the design. However, the study participants, Jimma University, and the zonal and district health offices were informed about the objectives of the study and agreed to conduct. Moreover, we have planned to disseminate the findings to the Jimma zonal and respective districts health offices.

\section{RESULTS}

\section{Sociodemographic and economic characteristics of} respondents

Of the 391 individuals who were approached, 360 participants were interviewed in the study giving a response rate of $92 \%$. The mean $( \pm \mathrm{SD})$ age of the study participants was $23.805 \pm 4.8$ years with a range of $15-45$ years. The majority of respondents was Muslims (326 (90.56\%)) and Oromo ethnic groups $(348(96.67 \%))$. Lower than a quarter of the respondents had no formal education (78 (21.67 $\%)$ ), while only $22(6.11 \%)$ had completed high school. Moreover, over half of the respondents (262 (72.78\%)) were housewives followed by merchants $(75(20.83 \%))$. Likewise, most of the respondents $(302(83.89 \%))$ had a family size of $2-5$ (table 2 ).

\section{Obstetrics and pregnancy-related characteristics}

All the study participants were first-trimester pregnant mothers (gestational age of 7-13 weeks) and the mean gestational age was 11 weeks \pm 4 days. Half of the respondents $(177(49.17 \%))$ had 1-2 live birth children and about 103 (28.61\%) were primigravida ladies. About 288 $(63.33 \%)$ of the participating mothers had $\leq 2$ years interpregnancy intervals (table 3 )

\section{Dietary practices of the study participants}

More than half (189 (52\%)) of the respondents had Owen home garden fruit/vegetables/for consumption and sale. Most of the respondents (289 (80\%)) did not avoid food during pregnancy and the majority of the respondents (314 $(87.22 \%)$ ) did not take iron folate tablets during early pregnancy. Almost all the respondents (357 (99.17\%)) didn't consume alcohol during pregnancy (table 4). 
Table 2 The sociodemographic and economic characteristics of dietary diversity among pregnant women in rural South-West Ethiopia, $2020(n=360)$

\begin{tabular}{|c|c|c|c|c|c|}
\hline \multirow[b]{3}{*}{ Variables } & \multicolumn{2}{|c|}{ Adequate dietary diversity } & \multirow{3}{*}{$\begin{array}{l}\text { Total } \\
\text { N (\%) }\end{array}$} & \multirow[b]{3}{*}{$x^{2}$} & \multirow[b]{3}{*}{$P$ value } \\
\hline & Yes & No & & & \\
\hline & $\mathbf{N}(\%)$ & $\mathbf{N}(\%)$ & & & \\
\hline \multicolumn{6}{|l|}{ Age in years } \\
\hline $15-20$ & $59(31.72)$ & $64(36.78)$ & $123(34.17)$ & 7.18 & 0.12 \\
\hline $21-24$ & $34(18.28)$ & 26 (14.94) & $60(16.67)$ & & \\
\hline $25-29$ & $83(44.62)$ & $72(41.38)$ & $155(43.06)$ & & \\
\hline $30-34$ & $0(0.00)$ & $5(2.87)$ & $5(1.39)$ & & \\
\hline $35-49$ & $10(5.38)$ & $7(4.02)$ & $17(4.72)$ & & \\
\hline \multicolumn{6}{|l|}{ Ethnicity } \\
\hline Oromo & $179(96.24$ & $169(97.67)$ & $348(96.67)$ & 4.09 & 0.39 \\
\hline Amhara & $3(1.61)$ & $2(1.15)$ & $5(1.39)$ & & \\
\hline Dawuro & $3(1.61)$ & $1(0.57)$ & $4(1.11)$ & & \\
\hline Yem & $1(0.54)$ & $2(1.15)$ & $3(0.84)$ & & \\
\hline \multicolumn{6}{|l|}{ Religion } \\
\hline Muslim & $162(87.10)$ & $164(94.25)$ & $326(90.56)$ & 6.19 & 0.045 \\
\hline Orthodox & 18 (9.68) & $9(5.17)$ & $27(7.50)$ & & \\
\hline Protestant & $6(3.23)$ & $1(0.57)$ & 7 (1.94) & & \\
\hline \multicolumn{6}{|l|}{ Maternal education } \\
\hline No formal education & $27(14.51)$ & $51(29.51)$ & $78(21.67)$ & 25.24 & $<0.001$ \\
\hline Elementary school & $87(46.77)$ & $89(51.15)$ & $176(48.89)$ & & \\
\hline Completed grade 8 & $34(18.28)$ & $15(8.62)$ & 49 (13.61) & & \\
\hline High school & $21(11.29)$ & $5(2.87)$ & $26(7.22)$ & & \\
\hline Completed high school and above & $17(9.13)$ & $14(8.04)$ & $31(8.61)$ & & \\
\hline \multicolumn{6}{|l|}{ Maternal occupation } \\
\hline Merchant & $41(22.04)$ & $34(19.54)$ & $75(20.83)$ & 4.85 & 0.30 \\
\hline Housewife & $135(72.58)$ & $127(72.99)$ & $262(72.78)$ & & \\
\hline Government employee & $5(2.69)$ & $2(1.15)$ & 7 (1.94) & & \\
\hline Student & $1(0.54)$ & $5(2.87)$ & $6(1.67)$ & & \\
\hline Daily labourer & $4(2.15)$ & $6(3.45)$ & $10(2.78)$ & & \\
\hline \multicolumn{6}{|l|}{ Marital status } \\
\hline Married & $186(100)$ & $173(99.43)$ & 359 (99.72) & 1.07 & 0.30 \\
\hline Widowed & $0(0.00)$ & $1(0.57)$ & $1(0.28)$ & & \\
\hline \multicolumn{6}{|l|}{ Family size } \\
\hline Less than five & $149(80.11)$ & $153(87.93)$ & $302(83.89)$ & 0.07 & 0.04 \\
\hline Six and above & $37(19.89)$ & $21(12.07)$ & $58(16.11)$ & & \\
\hline \multicolumn{6}{|l|}{ Husband's education } \\
\hline No formal education & $35(18.82)$ & $36(20.69)$ & $71(19.72)$ & 18.87 & 0.002 \\
\hline Completed grade 8 & $19(10.22)$ & 32 (18.39) & $51(14.17)$ & & \\
\hline High school & $35(18.82)$ & $10(5.75)$ & $45(12.50)$ & & \\
\hline Completed high school & $28(15.06)$ & $21(12.07)$ & $49(13.61)$ & & \\
\hline \multicolumn{6}{|l|}{ Household head } \\
\hline Man & $182(97.85)$ & $166(95.40)$ & $348(96.67)$ & 1.67 & 0.19 \\
\hline Woman & $4(2.15)$ & $8(4.60)$ & $12(3.33)$ & & \\
\hline Drinking water source & & & & & \\
\hline
\end{tabular}


Table 2 Continued

\begin{tabular}{|c|c|c|c|c|c|}
\hline \multirow[b]{3}{*}{ Variables } & \multicolumn{2}{|c|}{ Adequate dietary diversity } & \multirow{3}{*}{$\begin{array}{l}\text { Total } \\
\text { N (\%) }\end{array}$} & \multirow[b]{3}{*}{$x^{2}$} & \multirow[b]{3}{*}{$P$ value } \\
\hline & Yes & No & & & \\
\hline & $\mathbf{N}(\%)$ & $\mathbf{N}(\%)$ & & & \\
\hline Public tap & $22(11.83$ & $23(13.22)$ & 45 (12.50) & 7.18 & 0.06 \\
\hline Protected spring & $144(77.42)$ & $118(67.82)$ & $262(72.78)$ & & \\
\hline Pipe water & $13(6.99)$ & $27(15.52)$ & $40(11.11)$ & & \\
\hline River & $7(3.76)$ & $6(3.45)$ & $13(3.61)$ & & \\
\hline \multicolumn{6}{|l|}{ Mass media used } \\
\hline Yes & $181(97.31)$ & $167(95.98)$ & $348(96.67)$ & 0.49 & 0.48 \\
\hline No & $5(2.69)$ & 7 (4.02) & $12(3.33)$ & & \\
\hline \multicolumn{6}{|l|}{ Wealth index } \\
\hline Rich & $11(5.91)$ & $13(7.47)$ & $24(6.70)$ & 2.98 & 0.22 \\
\hline Medium & $127(68.28)$ & $129(74.14)$ & $256(71.10)$ & & \\
\hline Poor & $48(25.81)$ & 32 (18.39) & $80(22.20)$ & & \\
\hline \multicolumn{6}{|l|}{ Districts } \\
\hline Coffee producing & $80(43.01)$ & $63(36.21)$ & $143(39.72)$ & 1.73 & 0.18 \\
\hline Grain producing & $106(56.99)$ & $111(63.79)$ & $217(60.28)$ & & \\
\hline
\end{tabular}

Table 3 The obstetrics and pregnancy-related characteristics of pregnant women in rural South-West Ethiopia, 2020 ( $n=360)$

\begin{tabular}{|c|c|c|c|c|c|}
\hline \multirow[b]{2}{*}{ Variables } & \multicolumn{2}{|c|}{ Adequate dietary diversity } & \multirow{2}{*}{$\begin{array}{l}\text { Total } \\
\mathrm{n}(\%)\end{array}$} & \multirow[b]{2}{*}{$x^{2}$} & \multirow[b]{2}{*}{$P$ value } \\
\hline & Yes n (\%) & No n (\%) & & & \\
\hline \multicolumn{6}{|l|}{ Gestational age } \\
\hline$>8$ weeks & 7 (3.77) & $8(4.60)$ & $15(4.17)$ & 0.15 & 0.14 \\
\hline 8-13 weeks & $179(96.23)$ & $166(95.40)$ & $345(95.83)$ & & \\
\hline \multicolumn{6}{|l|}{ Interpregnancy interval } \\
\hline$<2$ years & $121(65.05)$ & $107(61.49)$ & $228(63.33)$ & 0.49 & 0.48 \\
\hline$>2$ years & 65 (34.95) & 67 (38.51) & $132(36.67)$ & & \\
\hline \multicolumn{6}{|l|}{ Parity of women } \\
\hline Primipara & $109(58.60)$ & $106(60.92$ & $215(59.72)$ & 0.23 & 0.97 \\
\hline 1-2 children & $34(18.28)$ & $31(17.82)$ & 65 (18.06) & & \\
\hline 3-4 children & $35(18.82)$ & $30(17.24)$ & $65(18.06)$ & & \\
\hline 5 and more children & $8(4.30)$ & $7(4.02)$ & $15(4.17)$ & & \\
\hline \multicolumn{6}{|l|}{ History of abortion } \\
\hline Yes & $32(17.20)$ & $37(21.26)$ & $69(19.17)$ & 0.95 & 0.32 \\
\hline No & $154(82.80)$ & $137(78.74)$ & $291(80.83)$ & & \\
\hline \multicolumn{6}{|l|}{ History of stillbirth } \\
\hline Yes & $8(4.30)$ & $10(5.75)$ & $18(5.00)$ & 0.39 & 0.39 \\
\hline No & 178 (95.70) & $164(94.25)$ & $342(95.00)$ & & \\
\hline \multicolumn{6}{|c|}{ History of caesarean section } \\
\hline Yes & $5(2.69)$ & $4(2.30)$ & $9(2.50)$ & 0.05 & 0.81 \\
\hline No & $181(97.31)$ & $170(97.70)$ & $351(97.50)$ & & \\
\hline \multicolumn{6}{|c|}{ History of nausea or vomiting } \\
\hline Yes & $83(44.62)$ & $65(37.36)$ & $148(41.11)$ & 1.96 & 0.16 \\
\hline No & 103 (55.38) & 109 (62.64) & $212(58.89)$ & & \\
\hline
\end{tabular}


Table 4 The dietary practices among pregnant women in rural South-West Ethiopia, $2020(n=360)$

\begin{tabular}{|c|c|c|c|c|c|}
\hline \multirow[b]{2}{*}{ Variables } & \multicolumn{2}{|c|}{ Adequate dietary diversity } & \multirow{2}{*}{$\begin{array}{l}\text { Total } \\
\mathbf{n}(\%) \\
\end{array}$} & \multirow[b]{2}{*}{$x^{2}$} & \multirow[b]{2}{*}{$P$ value } \\
\hline & Yes n (\%) & No $n(\%)$ & & & \\
\hline \multicolumn{6}{|l|}{ Own fruit/vegetable garden } \\
\hline Yes & $96(51.61)$ & $93(53.45)$ & $189(52.5)$ & 0.12 & 0.72 \\
\hline No & $90(48.39)$ & $81(46.55)$ & $171(47.5)$ & & \\
\hline \multicolumn{6}{|l|}{ Fruits and vegetables used } \\
\hline Sell all of it & $2(2.08)$ & $0(0.00)$ & $2(1.06)$ & 2.00 & 0.36 \\
\hline Sell part of it & $50(52.08)$ & $51(54.84)$ & $101(53.44)$ & & \\
\hline Use all for consumption & $44(45.83)$ & $42(45.16)$ & $86(45.5)$ & & \\
\hline \multicolumn{6}{|l|}{ Additional meal } \\
\hline Yes & $35(18.81)$ & $15(8.62)$ & $50(13.89)$ & 5.09 & 0.02 \\
\hline No & $151(81.18)$ & 159 (91.37) & $310(86.11)$ & & \\
\hline \multicolumn{6}{|c|}{ Changed food during pregnancy } \\
\hline Yes & $50(26.88)$ & $39(22.41)$ & 89 (24.72) & 0.96 & 0.32 \\
\hline No & $136(73.12)$ & $135(77.59)$ & $271(75.28)$ & & \\
\hline \multicolumn{6}{|l|}{ Avoid food during pregnancy } \\
\hline Yes & $38(20.43)$ & $33(18.97)$ & $71(19.72)$ & 0.12 & 0.72 \\
\hline No & $148(79.57)$ & $141(81.03)$ & $289(80.28)$ & & \\
\hline \multicolumn{6}{|l|}{ Types of foods avoided } \\
\hline Sugar cane & $20(51.28)$ & $12(36.36)$ & $32(44.44)$ & 1.99 & 0.36 \\
\hline Avocado & $10(25.64)$ & $9(27.27)$ & $19(26.39)$ & & \\
\hline Tomato & $9(23.08)$ & $12(36.36)$ & $21(29.17)$ & & \\
\hline \multicolumn{6}{|l|}{ Reason for food avoidance } \\
\hline Big baby & $33(86.84)$ & $21(63.64)$ & $54(76.06)$ & 9.36 & 0.02 \\
\hline Maternal obesity & $0(0.00)$ & $2(6.06)$ & $2(2.82)$ & & \\
\hline Fetal discolouration & $0(0.00)$ & $5(15.15)$ & $5(7.04)$ & & \\
\hline Cause parasite & $5(13.16)$ & $5(15.15)$ & $10(14.08)$ & & \\
\hline \multicolumn{6}{|l|}{ Take iron folates } \\
\hline Yes & $28(15.05)$ & $18(10.34)$ & $46(12.78)$ & 1.78 & 0.18 \\
\hline No & $158(84.95)$ & $156(89.66)$ & $314(87.22)$ & & \\
\hline \multicolumn{6}{|l|}{ Coffee consumption } \\
\hline Yes & $162(87.10)$ & $152(87.36)$ & $314(87.22)$ & 0.05 & 0.95 \\
\hline No & $24(12.90)$ & $22(12.64)$ & $46(87.22)$ & & \\
\hline \multicolumn{6}{|l|}{ Khat chewing } \\
\hline Yes & $45(24.19)$ & 40 (22.99) & $85(23.61)$ & 0.07 & 0.78 \\
\hline No & $141(75.81)$ & $134(77.01)$ & 275 (76.39) & & \\
\hline \multicolumn{6}{|l|}{ Alcohol consumption } \\
\hline Yes & $2(1.08)$ & $1(0.57)$ & $3(0.83)$ & 0.27 & 0.60 \\
\hline No & $184(98.92)$ & $173(99.43)$ & $357(99.17)$ & & \\
\hline
\end{tabular}

\section{Women Minimum Dietary Diversity Score}

The overall magnitude of adequate dietary diversity intake among pregnant women was found to be $186(51.70 \%$; $95 \% \mathrm{CI} 46.10 \%$ to $56.40 \%)$ whereas, inadequate dietary diversity was observed among 174 (48.33\%; $95 \%$ CI $43.60 \%$ to $53.90 \%$ ) pregnant mothers (figure 2).
Factors associated with maternal dietary diversity

In the bivariate analysis, adequate maternal dietary diversity was significantly associated with women attending elementary school $(\mathrm{p}=0.030)$, completed grade $8(p \leq 0.001)$, attending high school $(p \leq 0.001)$, and completed high school and above $(\mathrm{p}=0.055)$ compared with those who were unable to read and write. Similarly, 


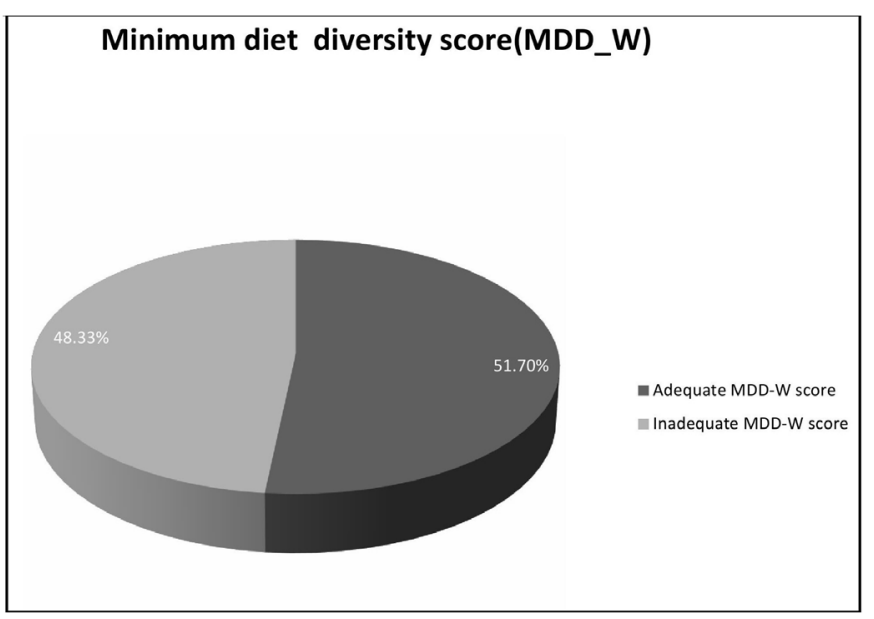

Figure 2 The minimum dietary diversity score among pregnant women of Jimma Zone, South-West Ethiopia, 2020.

pregnant women whose husbands attended high school $(\mathrm{p}=0.003)$ were significantly associated with the intake of adequate dietary diversity compared with those whose husbands had no formal education. The bivariate analysis further revealed that women having a family size of less than five were significantly associated with adequate dietary diversity $(\mathrm{p}=0.046)$ compared with those who had six and above. Likewise, pregnant women who started an additional meal were significantly associated with adequate dietary diversity $(\mathrm{p}=0.025)$ compared with those who did not (table 5).

After controlling for other variables, adequate dietary diversity was significantly associated with attending elementary education (AOR=2.45; 95\% CI 1.33 to 4.51), completing grade 8 (AOR $=6.05 ; 95 \%$ CI 2.65 to 13.80$)$, attending high school (AOR=11.69; 95\% CI 3.76 to 36.27), completing high school and above $(\mathrm{AOR}=2.92$; 95\% CI 1.16 to 7.32 ), husbands attending high school (AOR=2.92; 95\% CI 1.15 to 7.47), family size of less than five (AOR $=3.44 ; 95 \%$ CI to 1.77 to 6.66$)$ and not had additional meal during pregnancy $(\mathrm{AOR}=0.42 ; 95 \%$ CI 0.21 to 0.83) (table 5)

\section{DISCUSSION}

This study aimed to assess the magnitude of dietary diversity and associated factors among pregnant women in the

Table 5 The binary and multivariable logistic regression modelling of predictors of dietary diversity among pregnant women in rural South-West Ethiopia, $2020(n=360)$

\begin{tabular}{|c|c|c|c|c|c|c|}
\hline \multirow[b]{2}{*}{ Variables } & \multicolumn{2}{|c|}{ Adequate dietary diversity } & \multirow[b]{2}{*}{$\mathbf{P}$} & \multirow[b]{2}{*}{$\operatorname{COR}^{\star}(95 \% \mathrm{Cl})$} & \multirow[b]{2}{*}{$P$ value } & \multirow[b]{2}{*}{ AOR† (95\% Cl) } \\
\hline & Yes $(n=186$ & No $(n=174)$ & & & & \\
\hline \multicolumn{7}{|l|}{ Maternal education } \\
\hline Elementary school & $87(46.77)$ & $89(51.15)$ & $0.030^{*}$ & 1.846 (1.06 to 3.20$)$ & $0.004 \uparrow$ & 2.45 (1.3 to 4.51$)$ \\
\hline Completed grade 8 & $34(18.28)$ & $15(8.62)$ & $<0.001^{*}$ & 4.28 (1.99 to 9.20$)$ & $<0.001 \dagger$ & $6.05(2.65$ to 13.80$)$ \\
\hline \multicolumn{7}{|l|}{ Husband's education } \\
\hline No formal education & $35(18.82)$ & $36(20.69)$ & & Ref & & Ref \\
\hline Elementary school & $69(37.10)$ & $75(43.10)$ & 0.849 & 0.94 (0.53 to 1.67$)$ & 0.846 & 0.93 (0.50 to 1.75$)$ \\
\hline Completed grade 8 & $19(10.22)$ & $32(18.39)$ & $0.188^{*}$ & 0.61 (0.29 to 1.27$)$ & 0.057 & 0.44 (0.19 to 1.02$)$ \\
\hline \multicolumn{7}{|l|}{ Family size } \\
\hline Less than five & $149(80.11)$ & $153(87.93)$ & $0.046^{*}$ & 1.809 (1.01 to 3.23$)$ & $<0.001 \dagger$ & $3.4(1.77$ to 6.66$)$ \\
\hline Six and above & $37(19.89)$ & $21(12.07)$ & & Ref & & Ref \\
\hline \multicolumn{7}{|l|}{ Wealth index } \\
\hline Rich & $11(5.91)$ & $13(7.47)$ & 0.222 & $0.56(0.22$ to 1.41$)$ & 0.589 & 0.74 (0.25 to 2.15$)$ \\
\hline Medium & 127 (68.28) & $129(74.14)$ & $0.106^{*}$ & 0.65 (0.39 to 1.09$)$ & 0.578 & 0.84 (0.46 to 1.53$)$ \\
\hline Poor & $48(25.81)$ & 32 (18.39) & & Ref & & Ref \\
\hline \multicolumn{7}{|l|}{ Additional meal } \\
\hline Yes & $35(18.81)$ & 15 (8.62) & & Ref & & Ref \\
\hline No & 151 (81.18) & 159 (91.37) & $0.006^{\star}$ & 0.40 (0.21 to 0.77$)$ & $0.012 \dagger$ & 0.41 (0.20 to 0.82$)$ \\
\hline
\end{tabular}

*Significant in binary analysis.

†Significant in multivariable logistic regression.

AOR, adjusted OR; COR, crude OR; Ref, reference category. 
rural communities of Jimma Zone, South-West Ethiopia. Pregnancy is a critical period which demands adequate dietary diversity to prevent undernutrition across generations. ${ }^{2}$ Adequate dietary diversity during pregnancy is a very important key to meet the increased demands of nutrients and prevent unwanted consequences. ${ }^{9}$ In our study, we observed that almost half of the mothers $(51.7 \%$ (95\% CI $46.1 \%$ to $56.4 \%$ )) had adequate minimum dietary diversity scores. The current result agrees with studies from Arsi Zone, Ethiopia which was $50.26 \%{ }^{28}$ whereas it was higher than the prevalence reports from Bale Zone, Ethiopia 44.8\%, ${ }^{29}$ Shashemene Oromia, Ethiopia $25.4 \%,{ }^{7}$ East Gojam Zone, Ethiopia $45 \%,{ }^{12}$ West Gojam, Northwest Ethiopia $46.4 \%{ }^{30}$ and Ghana $40.3 \% .^{31}$ On the other hand, it was lower than the observations reported from the public health facility of Nekemte town $(73.11 \%),{ }^{32}$ Kembata Tembaro public health centre southern Ethiopia (79.9\%), ${ }^{33}$ Alamata General Hospital of Tigray Ethiopia $(61.2 \%)^{14}$ and Islamabad, Pakistan $(89 \%) .{ }^{34}$ All these discrepancies might be because of the variations in the dietary diversity score measurement tools, and geographical and seasonal variations. ${ }^{35}$

In the present study, we found that adequate dietary diversity during pregnancy was significantly associated with maternal education. Thus, pregnant women who attended elementary schools, junior schools and high schools had two times (AOR=2.45, 95\% CI 1.3 to 4.51 ), six times (AOR=6.05, 95\% CI 2.65 to 13.8) and three times ( $\mathrm{AOR}=2.9,95 \%$ CI 1.16 to 7.32 ) more likelihood of having adequate dietary diversity than those who did not attend formal education, respectively (table 5). Similar findings were also observed in studies carried out by several other investigators. Accordingly, a study from Shashemen, Central Oromia region shows that adequate dietary diversity was 3.18 times among women who attended tertiary school. ${ }^{7}$ Similarly, a report from the rural community of Ilu Aba Bor Zone, Ethiopia, showed that adequate dietary diversity during pregnancy was 3.4 times more among women who attended secondary school than those who did not attend formal education. ${ }^{10}$ In the same way, the study carried out in Jille Tumuga, North-East Ethiopia indicated that pregnant women who attended some educational level were 2.33 times more likely to attain adequate dietary diversity than those who did not. ${ }^{16}$ Another study from Kenya Referral Hospital revealed that women who attended secondary school were 2.78 times more likely to attain adequate dietary diversity. ${ }^{13}$ Likewise, a report from the Indian slum of Kolkata showed that women who attended higher educational levels were 2.83 times more likely to attain adequate dietary diversity than those who have no formal education. ${ }^{36}$ Furthermore, a study from southern Bangladesh reported that women who completed secondary school were 2.8 times more likely to consume a diversified diet. ${ }^{11}$ This could be because mothers who had some educational level had better awareness about the importance of diet diversity and added diversified food to their meal during pregnancy. ${ }^{37}$ In addition to this, educated mothers might have better jobs which can affect the household wealth and subsequently affect the adequacy of maternal dietary diversity. ${ }^{1015}$

In the same way, pregnant women whose husbands attended some high school grades were three times more likely to have adequate dietary diversity during pregnancy compared with women whose husbands had no formal education (table 5). This finding is supported by reports from Alamata General Hospital, northern Ethiopia, that show that pregnant women, whose husbands attended high school and above, were 2.8 times more likely to consume a diversified diet. ${ }^{14}$ Likewise, a report from Tanzania showed the association between women's diet diversity and husbands' education level. ${ }^{38}$ This could be due to the fact that women whose husbands had attended high school might have better access to information regarding the importance of dietary diversity during pregnancy.

Similarly, the current study revealed that having a family size of less than five was significantly associated with adequate maternal dietary diversity. Thus, women who had less than five family members were three times more likely to have adequate dietary diversity compared with women who had a family size of six and above (table 5). This was supported by evidence from Ilu Aba Bora Zone, Ethiopia, which indicated that pregnant women with a family size of five and above were three times more likely to be undernourished. ${ }^{10}$ Another similar study from Woldia, North-East Ethiopia revealed that young adolescents living with five or more family sizes were 2.09 times more likely to consume an inadequate diet. ${ }^{39}$ In the same way, a report from the Indian slum of Kolkata showed that households having small family sizes were more than two times likely to attain adequate dietary diversity than those who have more. ${ }^{36}$ This might be due to a tendency for a woman to eat last and smaller portions to secure other household members. Another possible explanation could be a greater burden of care in households of large family sizes which could affect intake of adequate dietary diversity in pregnant women.

We also observed that pregnant women who had not yet started on an additional meal were $60 \%$ less likely to have an adequate diversified diet compared with those who have started on the additional meal (table 5). This finding concurs with studies conducted in the Illu Aba Bora Zone, Ethiopia which revealed that women who had three or more meals were 2.8 times more likely to had a diversified diet. ${ }^{10}$ Similarly, a report from Alamata General hospital, Ethiopia showed that pregnant women who had three or more meals per day were 2.6 times more likely to have an adequately diversified diet. ${ }^{14}$ This might be because pregnant women who consumed an additional meal per day have more chances of accessing different food groups.

After the implementation of the essential nutrition actions for the last 10 years by the government of Ethiopia, there is still nearly half of pregnant women meeting adequate dietary diversity. Thus, the findings of this study 
have practical implications on the interventions calls to revamp behaviour change communications by using different strategies to improve it. This study has several important strengths and limitations. It is a communitybased study proportionally allocated to the two known agroecology of the study area which makes it represent the true population and helps to inference the findings to the study area. However, because of the cross-sectional nature of the study, temporal or causal effect relationships established and seasonal variations were not considered. Moreover, the dietary diversity score was based on selfreport and it might be subjected to some level of recall bias. Nevertheless, the multiple pass 24 hours probing method was used to minimise the recall bias.

\section{CONCLUSIONS}

In this study, the dietary diversity of pregnant women was low as compared with the pooled proportion of dietary diversity among pregnant women conducted in Ethiopia. ${ }^{40}$ The mother being educated, husbands having attended high school grades, family size of less than five, and not having an additional meal during pregnancy were significantly associated with adequate dietary diversity. The results imply there is a need for strengthening and promoting female education through intersectoral collaborations and additional meal counselling during antenatal care follow-up. Also, dietary diversity interventions need to target women who have had no formal education, large family sizes and the importance of additional meals during pregnancy to improve inadequate dietary diversity. Moreover, the findings of the the present study suggest an association, not causality. Thus, further studies with more strong designs are needed.

Acknowledgements The authors thank Jimma University for its support during the research activities. The authors also thank the Oromia Health Bureau, Jimma Zone, and the two district health officials for their permission and support to conduct this study. The authors also thank the study participants, data collectors, supervisors, as well as colleagues for their cooperation and support during the research activities.

Contributors MNK was involved in the conception, design, data collection, analyses and writing the draft of the paper. DT and TB were involved in the design and analyses. MNK is responsible for the overall content of the manuscript as a guarantor; for the work and/ or the conduct of the study, had access to the data and controlled the decision to publish. All authors were involved in report writing and interpretation, and have reviewed and approved the final manuscript, and agreed for submission.

Funding The authors have not declared a specific grant for this research from any funding agency in the public, commercial or not-for-profit sectors.

Map disclaimer The inclusion of any map (including the depiction of any boundaries therein), or of any geographic or locational reference, does not imply the expression of any opinion whatsoever on the part of $B M J$ concerning the legal status of any country, territory, jurisdiction or area or of its authorities. Any such expression remains solely that of the relevant source and is not endorsed by BMJ. Maps are provided without any warranty of any kind, either express or implied.

\section{Competing interests None declared.}

Patient and public involvement Patients and/or the public were involved in the design, or conduct, or reporting, or dissemination plans of this research. Refer to the Methods section for further details.

Patient consent for publication Not applicable.
Ethics approval Ethical approval was obtained from Jimma University Institutional Review Board (IRB) with reference number IHRPGD/386/19 on 29 September 2019 and Oromia Regional Health Bureau. A permission letter was obtained from the Jimma Zone Health office. After explaining the purpose and objective of the study, written informed consent was obtained from each participant. Confidentiality and privacy were kept throughout the study. Confidentiality was assured by coding the questionnaire. The data were kept under a locked cabinet and were not disclosed to anyone except the investigators. The procedure constituted a minimal risk to the participants and it was explained before the onset of data collection.

Provenance and peer review Not commissioned; externally peer reviewed.

Data availability statement Data are available upon reasonable request.

Open access This is an open access article distributed in accordance with the Creative Commons Attribution Non Commercial (CC BY-NC 4.0) license, which permits others to distribute, remix, adapt, build upon this work non-commercially, and license their derivative works on different terms, provided the original work is properly cited, appropriate credit is given, any changes made indicated, and the use is non-commercial. See: http://creativecommons.org/licenses/by-nc/4.0/.

\section{ORCID iDs}

Melesse Niguse Kuma http://orcid.org/0000-0002-1417-8913

Tefera Belachew http://orcid.org/0000-0001-5455-9457

\section{REFERENCES}

1 WHO. Healthydiet_fact sheet who may ED. WHO, 2015: 1-6. http:// www.who.int/mediacentre/factsheets/fs394/en/

2 Bhutta ZA, Das JK, Rizvi A, et al. Evidence-Based interventions for improvement of maternal and child nutrition: what can be done and at what cost? Lancet 2013;382:452-77.

3 Sebastiani G, Herranz Barbero A, Borrás-Novell C, et al. The effects of vegetarian and vegan diet during pregnancy on the health of mothers and offspring. Nutrients 2019;11:557.

4 Drimie S, Faber M, Vearey J, et al. Dietary diversity of formal and informal residents in Johannesburg, South Africa. BMC Public Health 2013;13:911.

5 Ziyenda Katenga-Kaunda L, Iversen PO, Holmboe-Ottesen G, et al. Dietary intake and processes of behaviour change in a nutrition education intervention for pregnant women in rural Malawi: a clusterrandomised controlled trial. Public Health Nutr 2020;23:2345-54.

6 Mukherjee A, Paul S, Saha I. Dietary diversity and its determinants: a community-based study among adult population of Durgapur. West Bengal. Medical Journal of Dr DY Patil Vidyapeeth 2018;11:296-301.

7 Desta M, Akibu M, Tadese M, et al. Dietary diversity and associated factors among pregnant women attending antenatal clinic in Shashemane, Oromia, central Ethiopia: a cross-sectional study. $J$ Nutr Metab 2019;2019:1-7.

8 Haile A, Teshome A. Determinants of dietary diversity consumption and nutritional status of pregnant women attending armed forces comprehensive specialized Hospital, Addis Ababa, Ethiopia. Food Processing \& Nutritional Science 2020;1:51-79.

9 Gete DG, Waller M, Mishra GD. Effects of maternal diets on preterm birth and low birth weight: a systematic review. Br J Nutr 2020;123:446-61.

10 Tsegaye D, Tamiru D, Belachew T. Factors Associated with Dietary Practice and Nutritional Status of Pregnant Women in Rural Communities of Illu Aba Bor Zone, Southwest Ethiopia. Nutrition and Dietary Supplements 2020;12:103-12.

11 Shamim AA, Mashreky SR, Ferdous T, et al. Pregnant women diet quality and its sociodemographic determinants in southwestern Bangladesh. Food Nutr Bull 2016;37:14-26.

12 Yeneabat T, Adugna $\mathrm{H}$, Asmamaw T, et al. Maternal dietary diversity and micronutrient adequacy during pregnancy and related factors in East Gojjam zone, Northwest Ethiopia, 2016. BMC Pregnancy Childbirth 2019;19:173.

13 Kiboi W, Kimiywe J, Chege P. Determinants of dietary diversity among pregnant women in Laikipia County, Kenya: a cross-sectional study. BMC Nutr 2017;3.

14 Jemal K, Awol M. Minimum dietary diversity score and associated factors among pregnant women at Alamata General Hospital, Raya Azebo zone, Tigray region, Ethiopia. J Nutr Metab 2019;2019:8314359.

15 Djossinou DRA, Savy M, Fanou-Fogny N, et al. Changes in women's dietary diversity before and during pregnancy in southern Benin. Matern Child Nutr 2020;16:e12906.

16 Aliwo S, Fentie M, Awoke T, et al. Dietary diversity practice and associated factors among pregnant women in North East Ethiopia. BMC Res Notes 2019;12:123. 
17 Sharma R, Gaffey MF, Alderman H, et al. Prioritizing research for integrated implementation of early childhood development and maternal, newborn, child and adolescent health and nutrition platforms. J Glob Health 2017;7:011002.

18 Lee SE, Talegawkar SA, Merialdi M, et al. Dietary intakes of women during pregnancy in low- and middle-income countries. Public Health Nutr 2013;16:1340-53.

19 Ethiopian Public Health Institute Addis Ababa E. Ethiopia national food consumption survey, 2013. Available: https://www.scirp.org/ reference/ReferencesPapers.aspx?ReferencelD=1761819 [Accessed 09 Apr 2020]

20 Asayehu TT, Lachat C, Henauw SD, et al. Dietary behaviour, food and nutrient intake of women do not change during pregnancy in southern Ethiopia. Matern Child Nutr 2017;13:e12343.

21 Kedir H, Berhane Y, Worku A. Khat chewing and restrictive dietary behaviors are associated with anemia among pregnant women in high prevalence rural communities in eastern Ethiopia. PLoS One 2013;8:e78601.

22 Workicho A, Belachew T, Ghosh S, et al. Burden and determinants of undernutrition among young pregnant women in Ethiopia. Matern Child Nutr 2019;15:e12751.

23 Diddana TZ. Factors associated with dietary practice and nutritional status of pregnant women in Dessie town, northeastern Ethiopia: a community-based cross-sectional study. BMC Pregnancy Childbirth 2019;19:517.

24 Kuma MN, Tamiru D, Belachew T. Hemoglobin level and associated factors among pregnant women in rural Southwest Ethiopia. Biomed Res Int 2021;2021:1-11.

25 Goshu G, Teshome MS, Abate KH. Maternal dietary and nutritional characteristics as a predictor of newborn birth weight in Jimma town, Southwest Ethiopia, 2017. Journal of Public Health and Epidemiology 2018;10:155-64.

26 Suresh K, Chandrashekara S. Sample size estimation and power analysis for clinical research studies. J Hum Reprod Sci 2012;5:7.

27 FAO and FHI 360. Minimum dietary diversity for women: a guide for measurement. Rome, 2016. Available: www.fao.org/3/i5486e/i5486e. pdf [Accessed 09 Apr 2020].

28 Zerfu TA, Umeta M, Baye K. Dietary diversity during pregnancy is associated with reduced risk of maternal anemia, preterm delivery, and low birth weight in a prospective cohort study in rural Ethiopia. Am J Clin Nutr 2016;103:1482-8.
29 Hailu S, Woldemichael B. Dietary diversity and associated factors among pregnant women attending antenatal care at public health facilities in Bale Zone, Southeast Ethiopia]]\&gt. Nutrition and Dietary Supplements 2019;11:1-8.

30 Demilew YM, Alene GD, Belachew T. Dietary practices and associated factors among pregnant women in West Gojjam zone, Northwest Ethiopia. BMC Pregnancy Childbirth 2020;20:18.

31 Gyimah LA, Annan RA, Apprey C, et al. Dietary diversity and its correlates among pregnant adolescent girls in Ghana. medRxiv2020:1-27.

32 Girma S, Fikadu T, Agdew E, et al. Factors associated with low birthweight among newborns delivered at public health facilities of Nekemte town, West Ethiopia: a case control study. BMC Pregnancy Childbirth 2019;19:220.

33 Samuel S, Darebo T, Desta DT, et al. Socio-Economic and dietary diversity characteristics are associated with anemia among pregnant women attending antenatal care services in public health centers of Kembata Tembaro zone, southern Ethiopia. Food Sci Nutr 2020;8:1978-86.

34 Ali F, Thaver I, Khan SA. Assessment of dietary diversity and nutritional status of pregnant women in Islamabad, Pakistan. J Ayub Med Coll Abbottabad 2014;26:506-9.

35 McGowan CA, McAuliffe FM. Maternal dietary patterns and associated nutrient intakes during each trimester of pregnancy. Public Health Nutr 2013;16:97-107.

36 Pal M, Paul B, Dasgupta A. Dietary diversity among women of reproductive age: new evidence from an observational study in a slum of Kolkata. Int J Med Sci Public Health 2017:1.

37 Murakami K, Miyake Y, Sasaki S, et al. Education, but not occupation or household income, is positively related to favorable dietary intake patterns in pregnant Japanese women: the Osaka maternal and child health study. Nutr Res 2009;29:164-72.

38 Ochieng J, Afari-Sefa V, Lukumay PJ, et al. Determinants of dietary diversity and the potential role of men in improving household nutrition in Tanzania. PLoS One 2017;12:e0189022.

39 Endalifer ML, Andargie G, Mohammed B, et al. Factors associated with dietary diversity among adolescents in Woldia, northeast Ethiopia. BMC Nutrition 2021;7:1-8.

40 Hidru HD, Berwo Mengesha M, Hailesilassie Y, et al. Burden and determinant of inadequate dietary diversity among pregnant women in Ethiopia: a systematic review and meta-analysis. J Nutr Metab 2020;2020:1-10. 